\title{
Are elderly patients with diabetes at risk of hypoglycaemia when managed within the New Zealand guidelines for HbA1c?
}

Isabel Raiman, Miranda McDonald-Brown, Naomi van der Merwe, Kaye Boyd, Maureen Alleyne

\section{Background}

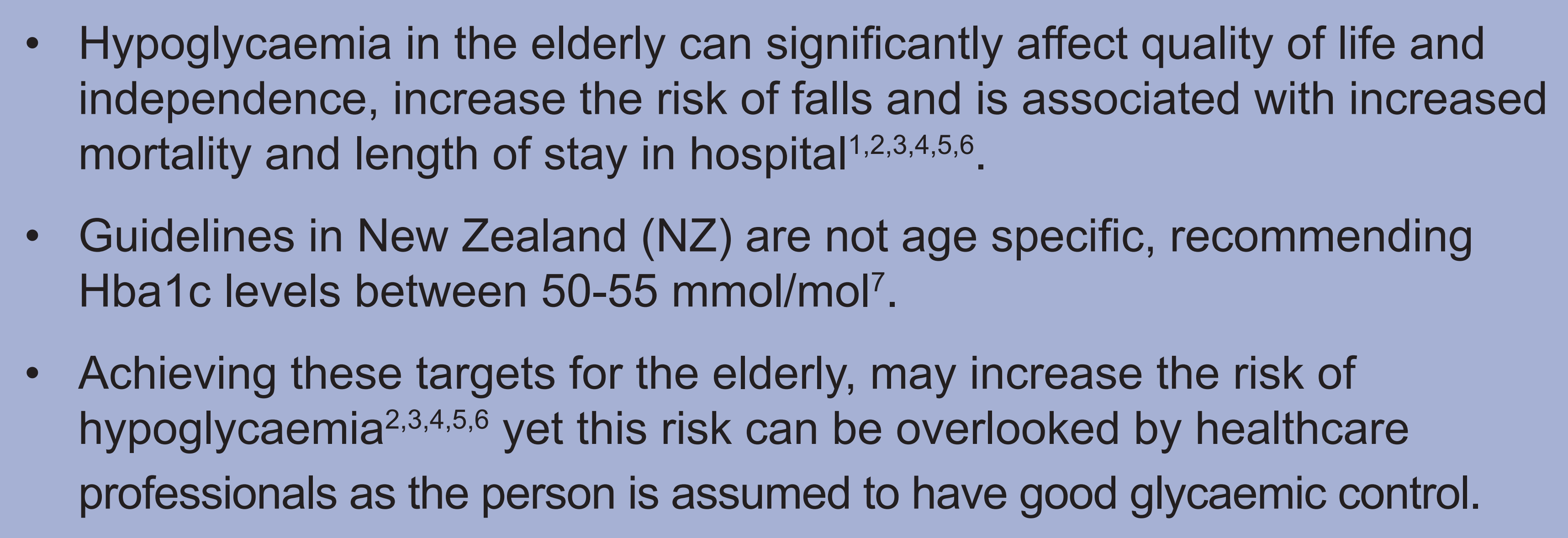

\section{Aim}

To identify elderly patients with diabetes (PWD) in the in-patient setting who are at risk of hypoglycaemia and intervene to decrease this risk.

\section{Methods}

- An electronic notification system was introduced, alerting the Diabetes Nurse Specialist (DNS) team of PWD admissions in the last 24 hours.

- Data such as age, HbA1c, eGFR, medications and comorbidities, was collected and assessed to identify elderly PWD at risk of hypoglycaemia.

- Those identified were clinically assessed and medications changes recommended when appropriate.

\section{Results}

- Data was collected and analysed over a three month period (1 October 2016 - 31 March 2017)

- A total of 405 PWD were admitted, $75 \%$ ( $n=304)$ of whom were elderly ( $\geq 65$ years).

Of those identified as elderly, $24 \%(n=72)$ were on $\geq 1$ OHAs or insulin with an $\mathrm{HbA} 1 \mathrm{c}$ of $\leq 55 \mathrm{mmol} / \mathrm{mol}$.

- Of those on glucose-lowering medication, $28 \%(n=20)$ had recorded or reported hypoglycaemia.

- A further $65 \%(n=47)$ were identified by the DNS as being at high risk of hypoglycaemia or hypoglycaemia unawareness.

In 93\% of elderly patients on glucose-lowering treatment with an $\mathrm{HbA} 1 \mathrm{c} \leq 55 \mathrm{mmol} / \mathrm{mol}$, the DNS reduced or stopped the medication or recommended looser glycaemic targets.

\section{Summary of key points}

- The NZ guidelines for HbA1c levels are not age specific and in this population allow only a narrow margin of safety ${ }^{2,3}$.

- Health professionals who treat to an $\mathrm{HbA} 1 \mathrm{c}$ target of $50-55 \mathrm{mmol} / \mathrm{l}$ may inadvertently increase the risk of iatrogenic hypoglycaemia in elderly patients ${ }^{2,3}$

\section{Recommendations}

- For elderly people with known risk factors for hypoglycaemia, an $\mathrm{HbA} 1 \mathrm{c}$ up to $70 \mathrm{mmol} / \mathrm{mol}(8.5 \%)^{3}$ may be more appropriate to decrease the risk of iatrogenic hypoglycaemia.

- Elderly patients should have more regular glycaemic reviews to monitor for hypoglycaemia or for the development of risk factors that increase the risk of hypoglycaemia.

Specific glycaemic targets for elderly patients on glucose-lowering agents should be made in the NZ Primary Care Handbook in accordance with international best-practice guidelines ${ }^{1,3,5,6}$.
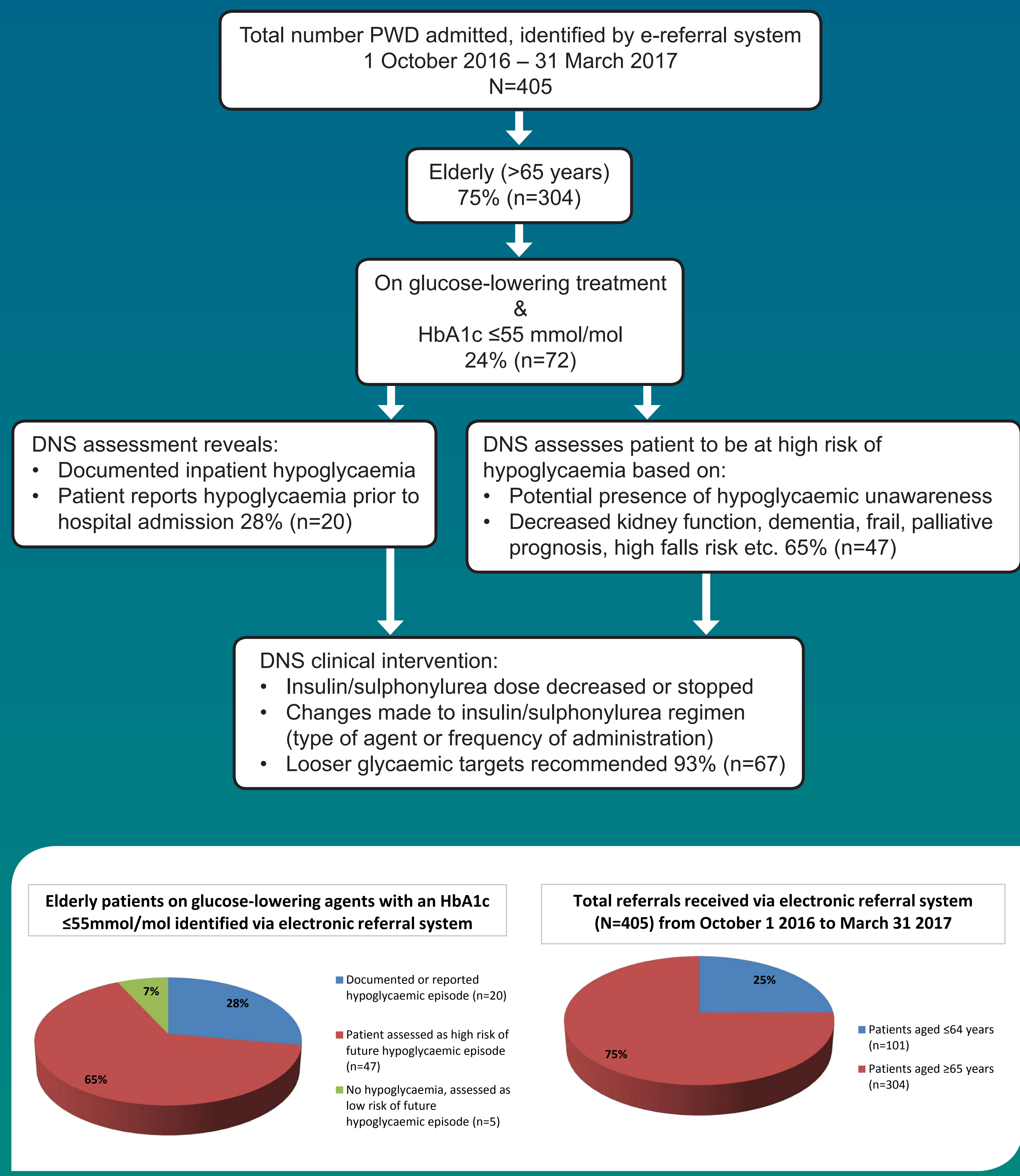

References:

'Abbatecola, A. \& Paolisso, G. (2009). Diabetes care targeis in olater persons. Dlabeles Research
and Clinical Practice, 865 , S35-S40. doi.10.1016 S0168-8227(09)70007-5

2Hambling, C. E., Seidu, S., Davies, M.J. \& Khunti, K. (2017). Older people with type 2 diabetes, including those with chronic kidney disease sulfonylurea or insulin therapies. Diabetic Medicine. Doi.10.1111/dme. 13380

3 International Diabetes Federation. (2013). Managing Older People With Type 2 Diabetes. Retrieved from: https://Www.idf.org/compon
attachments/attachments. html?id=985 "Kirkman, M. S., Briscoe, V., Clark, N., Florez, H. Haas, L., Halliter, J. ... \& S Swift, C. (2012). Diabetes in older adulis. Diabetes Care, 35(12). 2650-2657.
doi. 10.2337/dc12-1801
${ }^{5}$ Neumiller, J. \& Setter, S. (2009). Pharmacologic management of the older patient with type
2 diabetes mellitus. The America Journal of Geriatric Pharmasotherapy, 7(6). doi.10.1016 amjopharm.2009.12.002 'Sinclair, Al, Morley, J., Rodriguez-Manas, L., Paolisso, G., Bayer, T., Zeyfang, A. ... \& Lorig K. (2012). Diabetes Mellitus in older people: Position statement on behalf of the International Association of Gerontology and Geriatrics (IAGC) the European Diabetes Working Party for Older People (EDWPOP), and the International Task Force of Experts in Diabetes. Journal of the American Diabeles Association, 13(2012). 497-502. doi.10/1016/j.jamda.2012.04.012 TNew Zealand Guidelines Group. (2012). New Zealand Primary Care Handbook 2012. 3rd ed. Wellington: New Zealand Guidelines Group.

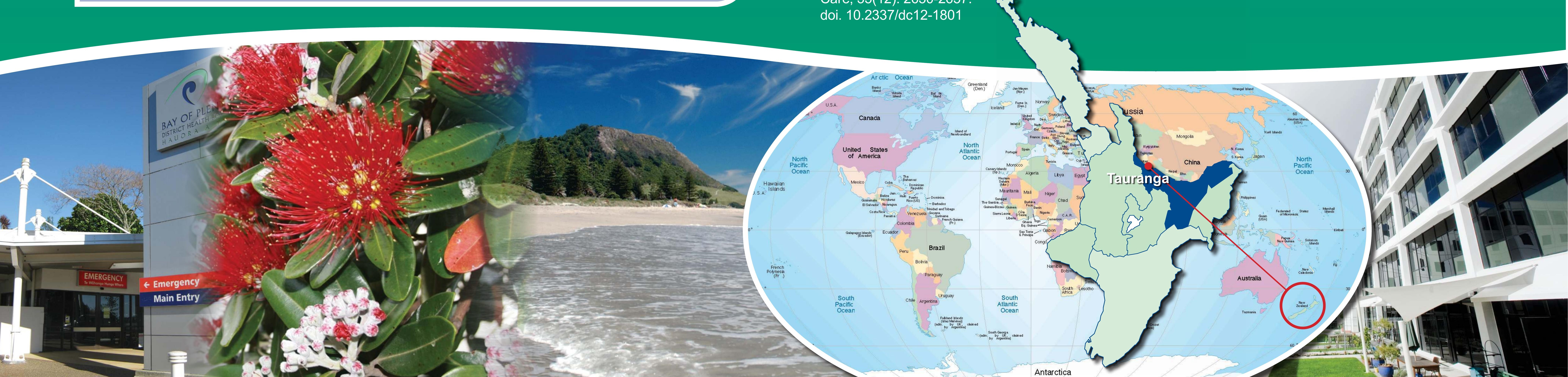

